\title{
An Assessment of the Awareness of Sexual and Reproductive Rights among Adolescents in South Western N igeria
}

\author{
M unirat A yok a 0 gunlayi
}

\begin{abstract}
This study, conducted in I keja and I korodu L ocal G overnment A reas of Lagos State, examined the awareness of sexual and reproductive rights among adolescents in south-western $\mathrm{N}$ igeria. A total of $600 \mathrm{in}$-school and out-ofschool adolescents were interviewed using quantitative and qualitative methods. Thestudy revealed that majority of the adolescents were aware of sexual and reproductive health rights $(60.3 \%$ in I keja L G A and $62.3 \%$ in I korodu LG A) but lacked knowledge of contents of the rights. M ajority of them in various categories (by school condition and type of settlement) were not aware of sexual and reproductive health programmes being implemented for adolescents. In addition, those who were aware of such intervention programmes could not access or use the services due to certain sociocultural barriers. The study recommends formulation of appropriate intervention strategies and programmes for adolescents so that they may be aware and knowledgeable of their sexual and reproductive rights. (A fr J R eprod H ealth 2005; 9[1]: 99-112)
\end{abstract}

\section{RÉSUMÉ}

E valuation de la conscience des droits sexuels et de reproduction chez les adolescents au sud-ouest du $\mathrm{N}$ igéria. Cette étude qui a été menée au sein des administrations locales d'I keja et d'I korodu dans I'E tat de Lagos, a examinéla conscience des droits sexuels et de reproduction chez les adolescents au Sud-ouest du $\mathrm{N}$ igéria. A l'aide d'une technique d'échantillon aléatoire, 600 répondants au total ont été interviewés. N ous avons organisé 12 discussions à groupe cible (D G C) parmi les adolescents qui étaient des internes et des externes à l'école. L'étudea montré que la majorité des adolescents étaient au courant des droits sexuels et de reproduction $(60,3 \%$ dans I'administration locale d'I keja et $62,3 \%$ dans l'administration locale d'I korodu) mais étaient ignorants du contenu des droits. La plupart d'entre eux dans les catégories différentes (selon les conditions de l'école et selon le genre d'habitation) n'étaient pas au courant des programme de la santé sexuelle et de reproduction qu'on mettait en place en faveur des adolescents. D e plus, ceux qui étaient au courant de tels programmes ne pouvaient pas avoir accès aux services et ne pouvaient pas s'en servir à cause des certains obstacles socio-culturels. L'étude préconise la formulation des stratégies et des programmes d'intervention appropriés pour les adolescents pour qu'ils puissent avoir la conscience et qu'ils puissent y connaitre en matière de leurs droits sexuels et de reproduction. (R ev A fr Santé Reprod 2005; 9[1]: 99-112)

KeY W ORDS: A dolescents, in-school, out-of-school, sex, rights, barriers

Correspondence: $M$ unirat A yok a 0 gunlayi, D epartment for International D evelopment (D F I D ) N igeria, P lot 607 B obo Street, $O$ ff G ana Street, P. O. B ox 4808, M aitama, A buja, N igeria. Tel: 2349 4137710-19 (ext. 2205); Fax: 2349 4137400; E-mail: m-ogunlayi@ dfid.gov.uk, iamogunlayi@ hotmail.com 


\section{Introduction}

In the last few years, interest in adolescent health has begun to grow in developing countries. Concern about their sexual and reproductive health is great, partly because of real or perceived increases in their sexual activity and rates of pregnancy outside marriage, and partly because of high rates of HIV infection among adolescents. ${ }^{7,11,21}$ D espite the near universal adult discomfort with the subject, consensus has begun to build in many countries that young people need expanded information, skills and services concerning sexual and reproductive health.

Concerns within the health community about the alarming increase in the numbers of HIV infected youth, particularly females, have led to research on adolescent sexual behaviour and reproductive health. A dolescents' knowledge of reproductive biology and health is critical to their ability to protect themselves from unwanted reproductive outcomes. While such knowledge is not sufficient to prevent such outcomes, it is the right and need of every adolescent to possess this information.

In addition, research conducted in 1992 on policies and legislation affecting adolescents in $\mathrm{N}$ igeria revealed that adolescents were far from being accorded the basic expected human rights as stated in the internationally agreed instruments formulated by the U nited N ations. ${ }^{14}$ Since they are members of the family, which is a unit of the society, they deserve some fundamental human rights to promote their health.

\section{Literature R eview}

In recent decades, most nations have come to recognise and accept the right of their citizens to reproductive health. A ccordingly, they have signed treaties and accords, and endorsed the programmes of conferences on population and development. Speaking of adolescents, the Programme of Action is quite specific. ICPD (1994) paragraph 7.44 calls on countries to "address adolescent sexual and reproductive health issues, including unwanted pregnancy, unsafe abortion and STD S, including HIV / AID S, through the promotion of responsible and healthy reproductive and sexual behaviour, including voluntary abstinence, and the provision of appropriate services and counselling specifically for that age group in order to substantially reduce all adolescent pregnancies".

It must be realised that 1994 Cairo ICPD marked a turning point for reproductive health. For the first time, sexual and reproductive rights were internationally recognised by governments, as contained in the international human rights documents. These rights rest on the recognition of the basic right of all couples and individuals to decide freely and responsibly the number, spacing and timing of their children. They also rest on the right to have the information and means to do so, and the right to attain the highest standard of sexual and reproductive health. $M$ ales and females have the right to be informed and have access to safe, effective, affordable and acceptable methods of their choice for the regulation of fertility, as well as access to health care for safe pregnancy and childbirth.

Respecting adolescents involves according them the right to participate in making decisions that affect their lives and the lives of their communities, including the right to share in the process of making decisions about their sexual well being. Although it would be naive to think that children making their own decisions will solve everything, it is important to include their meaningful participation in constructing a healthy culture of their own sexual relationship. Possibly, only through the institution of more democratic forms of adolescents' participation will they be able to enter into a real partnership with adults and ultimately be in a position to safeguard their health and make responsible decisions in their own interests. ${ }^{17}$

Theabovestated reproductivehealth problems, i.e., unintended pregnancies and incidence of STD s/ HIV/AIDS, which are associated with adolescents in developing countries particularly $\mathrm{N}$ igeria, were not unconnected with problems

A frican Journal of Reproductive $\mathrm{H}$ ealth $\mathrm{V}$ ol. $9 \mathrm{~N} 0.1 \mathrm{~A}$ pril 2005 
relating to accessibility of the vulnerable group to predisposing factors. Some elements of research findings and reports on the reproductive health information and services have been documented. The findings have established that educational level exerts a great influence on childbearing during the teen years. A bout $43.4 \%$ of $\mathrm{N}$ igerian women with no education give birth before age 20 years, compared with $6.9 \%$ of women with seven years of education..$^{18}$ Though over the past 15 years there has been little decline in the rates of teenage fertility in $\mathrm{N}$ igeria. ${ }^{16}$

The aforesaid influence of education and information on teenage pregnancy has close bearing to knowledge on contraception. A lthough adolescents' knowledge of contraception is increasing, their use lags far behind. ${ }^{16}$ A mong unmarried sexually active young women in $\mathrm{N}$ igeria, $11 \%$ use such methods. In a study of oral contraceptive use among female students aged 15-29 years, 92\% were aware of the method, yet only $17.5 \%$ had ever used it, and post-coital pills were the most popular. ${ }^{1}$ I $\mathrm{t}$ is clear that services are required to meet adolescents' reproductive health needs, yet adolescents throughout the world face limited access to such services. Young people's inexperience in when and how to use contraception, their lack of perception of it as relevant to their needs, and their expectation of a negative reaction was reviewed. ${ }^{20}$ It could then be confirmed that there is a great unmet need for services, but awareness and psychological access are essential. Several studies in Africa have reported difficulty in obtaining contraception, infrequent or unplanned sexual activity, opposition from partner and religious proscription $^{2,4,12}$ as the main reasons for low adoption of contraceptive usage. The above indices of adolescents' health status in $\mathrm{N}$ igerian states have suggested the need for individuals to accord adolescents the universal right to sexual and reproductive health, in order to reduce the risks of teenage pregnancies, STDS and HIV/ AIDS.

A frican Journal of Reproductive $\mathrm{H}$ ealth $\mathrm{V}$ ol. $9 \mathrm{~N} 0.1 \mathrm{~A}$ pril 2005
$O$ ne of the issues to be recognised by the Programme of Action, according to Family Care International ${ }^{6}$, is the needs and rights of adolescents to receive information and services. This is to enable them to manage their sexual and reproductive lives in a responsible and informed way, for them to lead healthy and fulfilling lives. ${ }^{5}$ I dentified lack of information or misinformation, adverse traditional practices, inaccessible and costly health care services and high fertility are the most important determinants of reproductive health in $\mathrm{N}$ igeria.

A big challenge that therefore lies ahead, according to IPPF, ${ }^{8}$ is further expansion into the areas of reproductive and sexual health as an integral component, knowing only too well how complex and culture-bound the issue of sexual health is. $\mathrm{H}$ aving justified the need for adolescents to access information and services, this study was conducted to assess and compare the knowledge of sexual and reproductive rights among adolescents.

\section{Study Areas}

The study was carried out in Lagos State, southwest $\mathrm{N}$ igeria. Two local government areas (LGAs), I keja and I korodu, were used as study sites. These LG As were chosen because of their level of urbanisation and rurality. I korodu LGA has a population of 181,914 (1992 provisional census figure). It is about $36 \mathrm{~km}$ north-east of Lagos and $26 \mathrm{~km}$ from I keja, the state capital. There are over 200 notable villages in I korodu LGA, which include the study sites, namely, Baiyeku, Gberigbe-O relade, I mota and 0 dogunyan. The people's predominant occupations include farming, fishing, hunting, with a considerable proportion engaging in trading and white-collar jobs. The population consists mainly of Yoruba, with other ethnic groups such as I bo and $\mathrm{H}$ ausa making up a substantial minority. $\mathrm{H}$ ealth care facilities were cited in these villages but none provided youth-friendly sexual and reproductive health services. There were 14 public secondary 


\section{A frican Journal of $\mathrm{R}$ eproductive $\mathrm{H}$ ealth}

schools and five government-approved private secondary schools as at the time of the study.

The history of the present I keja LGA is dated back to 1927 when the colonial government introduced tax collection. Since then, there has been a lot of metamorphosis and rationalisation that led to the re-creation of A gege, Shomolu, M ushin and A limosho LGAs, which were carved out of the then I keja D ivision. Consequently, the present I keja LGA is bounded in the north by A gege $L G A$, in the south by 0 shodi-I solo and M ushin LG As, in the east by Shomolu LG A, and on the west by Alimosho LGA. It has a population of 203,383 (1991 Population Census). The headquarters of I keja LGA is Alausa. It is worthy to note that I keja LGA is also the capital of Lagos State. Basically, I keja LG A has various (24) communities, some of which constitute the study sites, namely, A gidingbi, A bule 0 nigbagbo, $O$ lusosun and Ijaiye-O gba. The LGA is highly urbanised, the people are engaged in white-collar jobs, trading and other economic activities, with the major media houses in L agos State located in it. Some of these include D aily Times of N igeria, Lagos State Television, Eko FM and M urhi International Television (M iTV). These media houses have one programme or the other on youth including reproductive and sexual health.

There were many health care facilities evenly distributed in the area, including privately owned hospitals and non-governmental organisations that focus on reproductive health. There are 13 public and 16 private secondary schools approved by government in the state.

I keja LGA was chosen because of its outstanding development and availability of infrastructure and because it is mainly a Yoruba community with different ethnic groups inhabiting the LGA I I thus enhances objective comparative analysis with the other $L G A$. $O \mathrm{n}$ the other hand, I korodu LGA was chosen because of its level of rurality, as some of the communities lack certain infrastructures that are abundantly available in I keja LGA.
The two areas are different in terms of development, occupation, population and availability of infrastructures, cultural diversities and differential youth-friendly health carefacilities.

\section{M ethodology}

A multistage sampling technique was adopted to select the study population. Six hundred respondents, spread over the four schools selected and out-of-school adolescents, in rural and urban areas of Lagos State were selected for the study. Selection process was at four levels, mostly among the in-school adolescents. O ne rural and one urban LG A each were selected including both public and private secondary schools. The study schools were randomly selected in each LGA. The systematic sampling technique was used to select in-school adolescents in the selected schools to eliminate bias, while random sampling technique was used for sampling out-of-school adolescents, as some of them were not together as a group.

\section{Data Collection}

$D$ ata was collected using structured questionnaire and focus group discussions (FGDs). These provided information on knowledge, attitude, belief and practices related to sexual and reproductive rights of adolescents. The questionnaire was administered to both in-school and out-ofschool adolescents in the two LGAs. Q uestions were asked on the socio-demographic characteristics of respondents, awareness and knowledge of sexual and reproductive rights, sources of reproductive health information, relationship between adolescents' sexual and reproductive rights, and development and strategies for improving awareness about adolescents' sexual and reproductive rights. The questions were short and easy to understand. The author and some research assistants who understand the local languages administered the questionnaire after training and participation in the pre-test survey rehearsal.

A frican Journal of Reproductive $H$ ealth V ol. $9 \mathrm{~N} 0.1$ A pril 2005 
The study population included both male and female in-school adolescents aged 10-19 years and out-of-school adolescents aged 15-19 years. A ltogether, 600 copies of the questionnaire, which were found to be valid, were processed and analysed.

Focus group discussion was used to complement data obtained from the questionnaire. Twelve FGD sessions were conducted. E ach group discussion lasted for a minimum of 40 minutes and a maximum of one hour, depending on the response rate of participants and new insights from their discussions. At the end of each session, the recorder updated the notes and transcribed the tape recordings before submitting to the researcher who reviewed them.

\section{Data Analysis}

The data analysis examined social, cultural, economic and demographic factors responsible for knowledge and awareness of adolescents on their sexual and reproductive rights. The qualitative and quantitative data were integrated. The result of the FGDs was used in content analysis to observe frequencies and how normative and behaviour factors that influence sexuality and reproductive rights are emphasised. Q uantitative analysis was carried out after data cleaning and re-classification of some continuous variables had been done. The analysis focused on sets of variables: the antecedent sociocultural background, indicators for sexuality and reproductive rights, reproductive health needs of young people, and relationship of adolescents' sexual and reproductive rights and development. U nivariate and bivariate analyses were done using SPSS software.

Univariate analysis involved the use of simple statistics to examine the distribution of respondents according to some socio-cultural,

Table 1 Socio-Demographic Characteristics of Respondents (\%)

\begin{tabular}{lrrrrrr}
\hline Characteristic & In-school & $\begin{array}{c}\text { IkejaLGA } \\
\text { Out-of- } \\
\text { school }\end{array}$ & Total & In-school & $\begin{array}{r}\text { koroduLGA } \\
\text { Out-of- } \\
\text { school }\end{array}$ & Total \\
\hline Sex & 33.4 & 19.0 & 52.4 & 39.7 & 16.6 & 56.3 \\
$\quad$ M ale & 33.3 & 14.3 & 47.6 & 27.0 & 16.7 & 43.7 \\
$\quad$ Female & 66.7 & 33.3 & 100.0 & 66.7 & 33.3 & 100.0 \\
$\quad$ Total & & & & & & \\
A ge & 8.0 & - & 8.0 & 10.7 & - & 10.7 \\
10-14 & 58.7 & 33.3 & 92.0 & 56.0 & 33.3 & 89.3 \\
15-19 & 66.7 & 33.3 & 100.0 & 66.7 & 33.3 & 100.0 \\
$\quad$ Total & & & & & & \\
E ducational attainment & - & 0.4 & 0.4 & - & 4.3 & 4.3 \\
$\quad$ N o school & - & 0.6 & 0.6 & - & - & - \\
K oranic school & - & 8.3 & 8.3 & - & 13.0 & 13.0 \\
Primary & 3.0 & 8.7 & 11.7 & 5.4 & 7.3 & 12.7 \\
JSS & 63.7 & 15.3 & 79.0 & 61.3 & 8.7 & 70.0 \\
SSS & 66.7 & 33.3 & 100.0 & 66.7 & 33.3 & 100.0 \\
$\quad$ Total & & & & & & \\
M ain adtivity & 66.7 & - & 66.7 & 66.7 & - & 66.7 \\
$\quad$ Student & - & 18.3 & 18.3 & - & 19.3 & 19.3 \\
$\quad$ A pprentice & - & 13.7 & 13.7 & - & 7.0 & 7.0 \\
$\quad$ Worker & - & 1.3 & 1.3 & - & 7.0 & 7.0 \\
$\quad$ N one & 66.7 & 33.3 & 100.0 & 66.7 & 33.3 & 100.0 \\
$\quad$ Total & & & & & & \\
\hline
\end{tabular}


demographic and economic characteristics. F requency distributions and proportions were employed with a view to highlighting how varied the respondents were according to individual characteristics. Through the use of percentages, the univariate analysis was ableto providepreliminary answers to some of the research questions.

Bivariate analysis gave a simultaneous examination of two variables using crosstabulations. The relationships examined included: (1) socio-economic variables and awareness and knowledge of sexual and reproductive rights; and (2) cultural variables and knowledge of sexual and reproductive rights. Chi-square was used to test the association of socio-cultural factors with awareness and knowledge of sexual and reproductiverights and development of adolescents.

\section{Results and Discussion}

All the out-of-school respondents were aged 1519 years. Eight per cent and $10.7 \%$ of in-school adolescents in I keja and I korodu LGAS respectively were aged 10-14 years, while the others were aged 15- 19 years. In I keja LG A, the proportions of both male and female in-school respondents were equal ( $33.4 \%$ and $33.3 \%$ ), while there were $19 \%$ male and $14.3 \%$ female respondents among the out-of-school respondents (Table 1 ). In I korodu LGA, male in-school respondents were $39.7 \%$, while females were $27.0 \%$ because the number of male students in the schools sampled was higher.

Majority of the respondents were never married in both I keja (95.7\%) and Ikorodu $(94.6 \%)$ LG As. While $2.7 \%$ were married among in-school and 2\% among out-of-school respondents in I korodu, only $0.7 \%$ in-school and $0.3 \%$ out-of-school respondents were married in I keja LG A . In both I keja and I korodu LG As $0.2 \%$ each claimed that they were divorcees among the in-school adolescents.

$G$ reater percentages of the respondents were Christians $(70.7 \%$ in I keja and $67.7 \%$ in
I korodu), while M uslims constituted $29.3 \%$ and $32 \%$ in I keja and I korodu LG As. Yorubas constituted the greater percentage of the respondents, $65 \%$ in I keja and $80.3 \%$ in I korodu LGAs. The Ibos were $25.7 \%$ and $12.7 \%$ in I keja and I korodu respectively, while the $\mathrm{H}$ ausas among in-school respondents only constituted $0.3 \%$ each in I keja and I korodu LGAs. This is possibly because the two communities were predominantly Yoruba.

Majority of the respondents had attained, or were in, senior secondary classes, $79 \%$ in I keja and $70 \%$ in I korodu. O nly $11.7 \%$ and $12.7 \%$ in I keja and I korodu respectively were in, or had attained, junior secondary classes. Those who did not attend any school were $0.4 \%$ and $4.3 \%$ in I keja and I korodu respectively, while $0.6 \%$ had Q uranic education in both LGAs. Level of education of out-of-school respondents was lower in I korodu than Ikeja. D ata also reveals that majority of the parents of in-school respondents acquired secondary and postsecondary education. This factor may have contributed to the increased number of in-school respondents. More of the parents of out-ofschool respondents residing in I keja LG A attained secondary and post-secondary education than those residing in Ikorodu. This may be due to the higher level of development and urbanisation in I keja LGA. It may also be the reason that we had more out-of-school respondents who attained higher educational level in I keja than in I korodu LGA.

A bout $18.3 \%$ and $19.3 \%$ of out-of-school respondents in I keja and Ikorodu respectively were apprentices, while $13.7 \%$ and $7 \%$ were engaged in one income-earning job or the other, such as hawking, selling sand, barbing, car wash, cobbling, truck pushing, bus conducting, etc. However, $1.3 \%$ and $7 \%$ of out-of-school respondents in I keja and I korodu LGAs respectively were not engaged in any incomeearning activity.

A frican Journal of Reproductive $H$ ealth $V$ ol. $9 \mathrm{~N} 0.1$ A pril 2005 


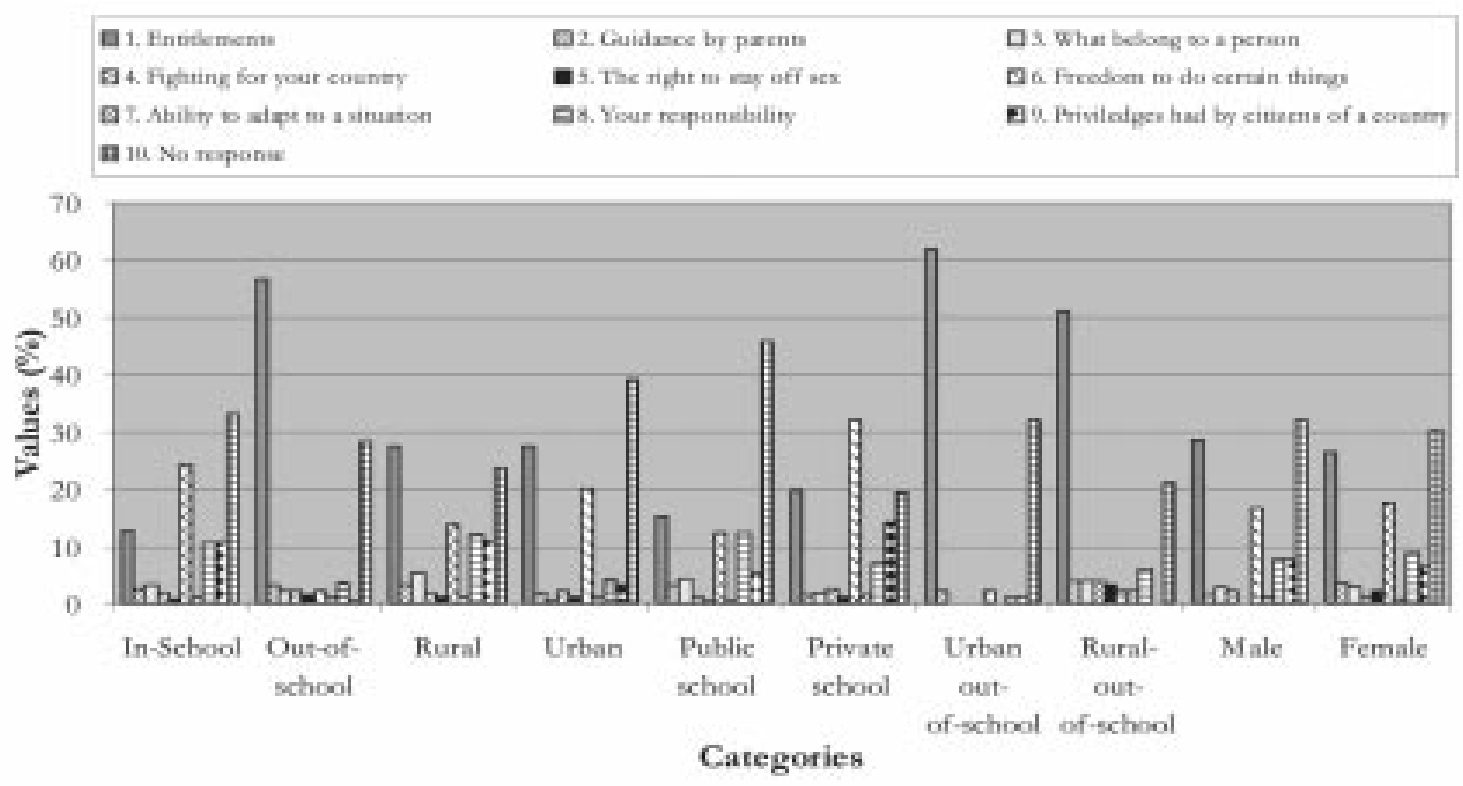

F igure 1 Respondents' Understanding of Rights

Knowledge of $A$ dolescent $S$ ex ual and $R$ eproductive $H$ ealth Rights

Respondents' understanding of sexual and reproductive health rights varied as shown in Figure 1. A high percentage of the respondents explained theword "rights" to mean entitlements. A greater percentage of out-of-school respondents $(56.5 \%)$, as compared to $12.8 \%$ among in-school respondents referred to right as entitlements. This is probably because the word "right" was translated into the local language for easy understanding by out-of-school respondents. This was followed closely by "freedom to do certain things" by $24.4 \%$ in-school, $2 \%$ out-of-school, and $13.7 \%$ and $20 \%$ by rural and urban respondents respectively. Majority of the respondents, however, did not respond to this question.

\section{$A$ wareness of $A$ dolescent $S e x$ ual and $R$ eproductive} Rights

$O \mathrm{n}$ the level of awareness of the rights of adolescents to sexual and reproductive health, $62.5 \%$ of in-school and $59.5 \%$ of out-of-school respondents said they were aware of sexual and reproductive rights. A greater number of inschool adolescents, and adolescents residing in rural areas, were aware of adolescent sexual and reproductive rights. However, chi-square statistical analysis revealed no significant difference $(p<$ 0.005 ) between the two genders, despite the fact that a higher number of male respondents were aware of adolescent sexual and reproductive rights. This finding does not support the proposition that adolescent females are more likely to seek information about sexual and reproductive rights than their male counterparts. Further analysis revealed a significant difference in the level of awareness among students in public and private schools, as adolescents attending public schools were more aware of adolescent rights to sexual and reproductive health than their peers in private schools. This may be attributed to the permission granted NGOs to work in public (government-owned) schools; government sees such services as part of social and extracurricular activities to the students. 
$\square$ e $\square$ e e $\square$ e e

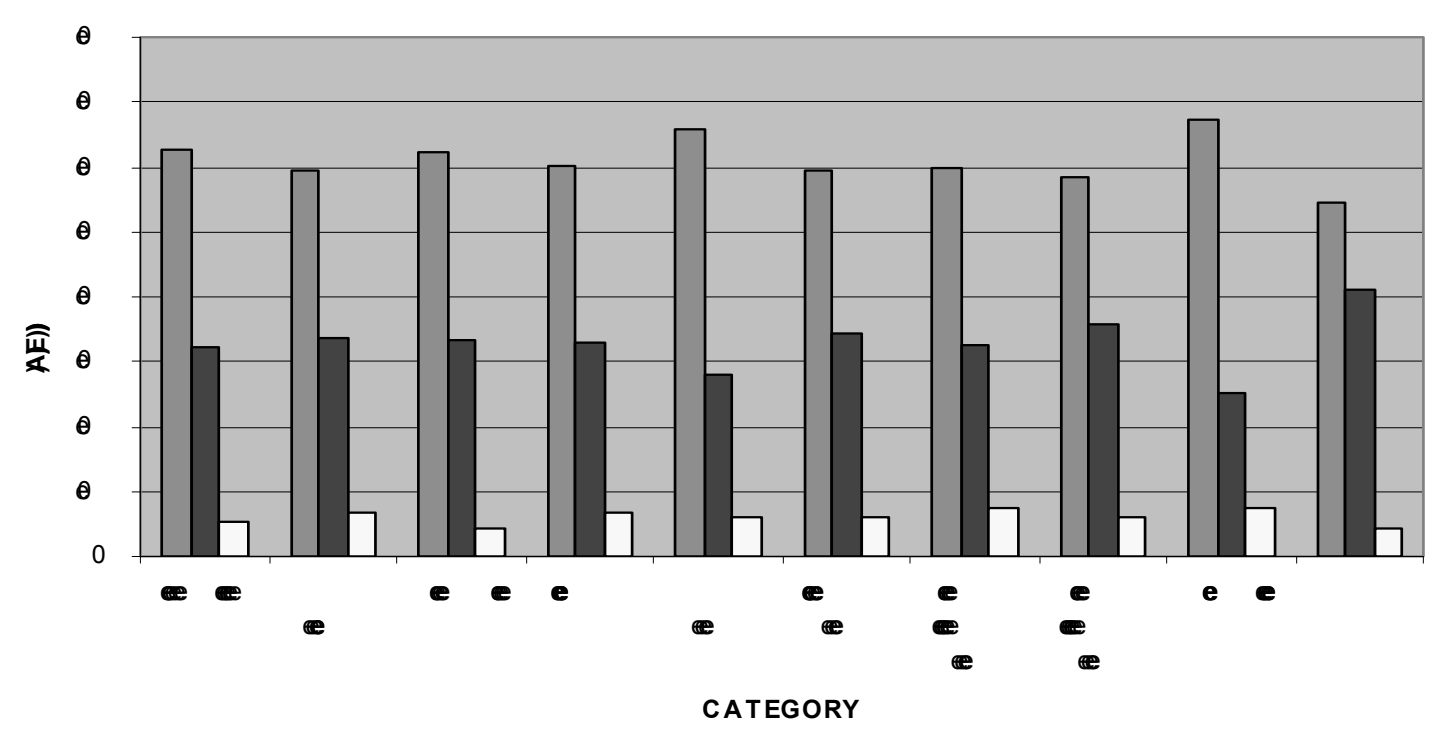

Figure 2 Awareness of Adolescents' Rights to Sexual and Reproductive $\mathrm{H}$ ealth

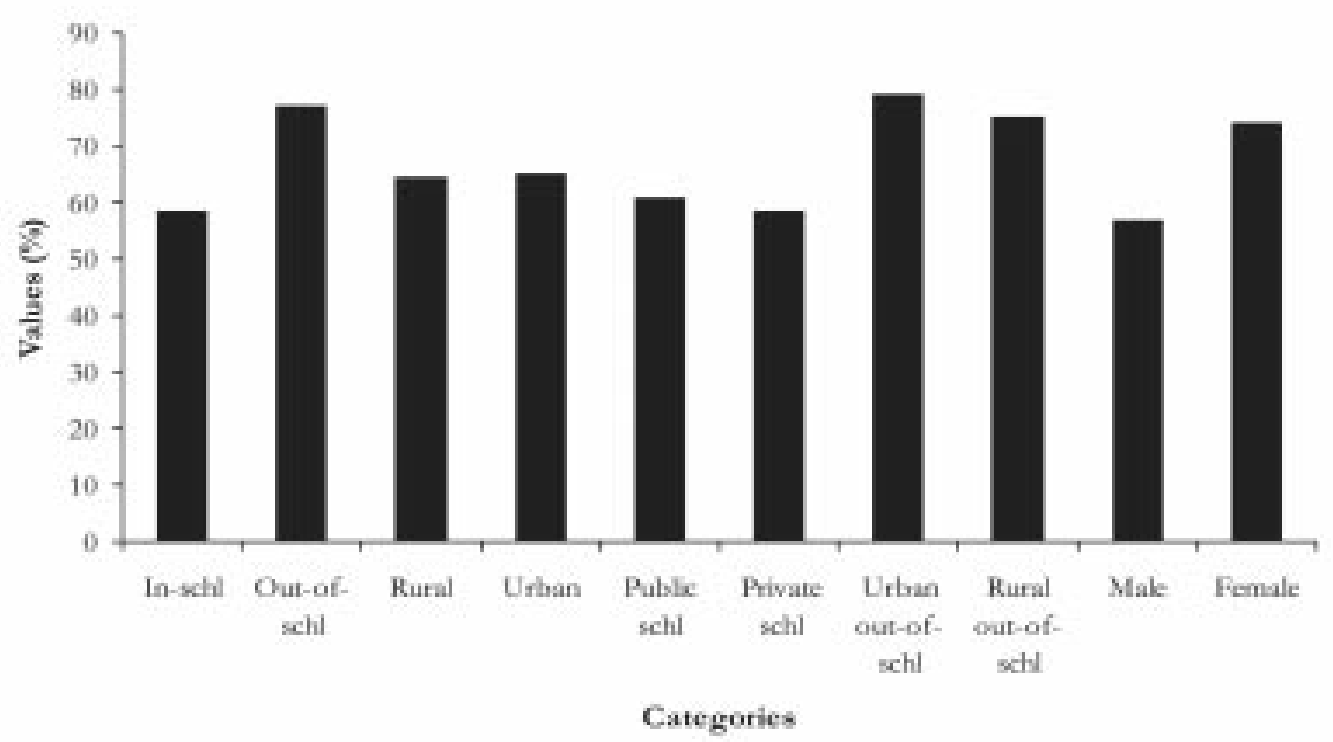

Figure 3 Respondents' O pinion on Lack of E ducation on $\mathrm{H}$ uman and Reproductive Rights

Further analysis also revealed that there was significant difference $(p>0.005)$ between the level of awareness of out-of-school adolescents living in urban centres and their counterparts residing in rural areas of I korodu $L G A$. This may be attributed to various advertisements, talk shows in the media and NGO work with informal sectors in urban centres. A respondent remarked: 


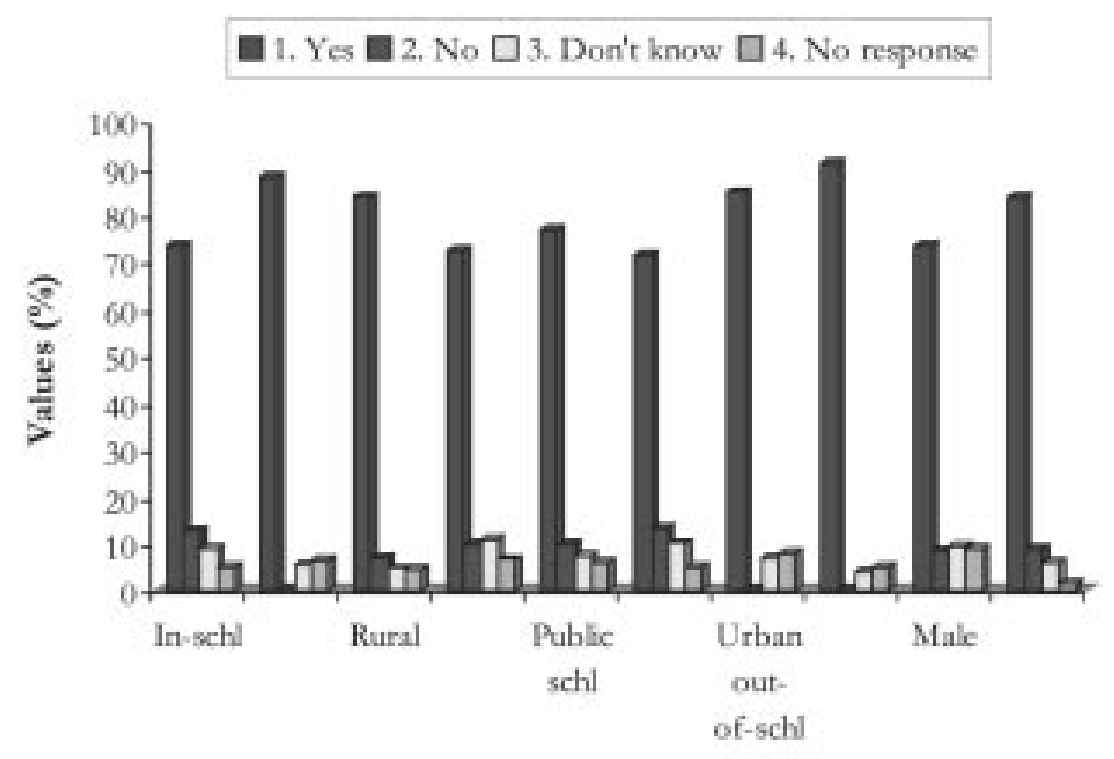

Categories

F igure 4 Respondents' O pinion on Sexual and Reproductive Rights and D evelopment

This type of education (sex uality education) has to start from the grassroots (from the village), as not many children attend schools. Therearestill thousands of peoplein therural areas who cannot read and write, so it has to start from the grassroots

Table 2 shows that respondents' understanding of reproductive health varied, although a higher percentage of respondents did not respond to this variable. The respondents referred to reproductive health as childbearing - $22.3 \%$ in-school, $29.5 \%$ out-of-school, $20.3 \%$ in rural and $29 \%$ in urban areas. While $13 \%$ of in-school and $3 \%$ of out-of-school adolescents referred to it as health of reproductive organs, others said it means "to born many children", "being physically sound", "knowledge of body and sexuality" and "the right way of doing things". These responses confirm that the respondents lacked knowledge of what reproductive health is, thus making their claim to know the meaning of sexual and reproductive rights questionable.
A higher proportion of the respondents did not identify any of the rights as their sexual and reproductive health rights, while a higher proportion of out-of-school adolescents residing in urban LG A were able to identify some of the rights. I rrespective of settlement (urban or rural) and schooling status (in-school or out-of-school), there was no significant difference $(p<0.005)$ between these variables and knowledge of what adolescent sexual and reproductive rights are. This may denote that, despite the fact that there was significance difference $(p>0.005)$ in the level of awareness, they had no knowledge of the contents of their rights. This further confirmed their lack of knowledge of reproductive health. FG D participants at a private school in I keja LG A answered thus in unison:

$\mathrm{N} 0$, we have not heard of adolescent sexual and reproductive rights, and we have not participated in programmes related to that either. If we are ex posed to such programmes, it would be nice, because we will be educated 
108 A frican Journal of $\mathrm{R}$ eproductive $\mathrm{H}$ ealth

about our health and our knowledge will becomemoresuperior, and will benefit from it tremendously.

A major factor identified by respondents for their lack of knowledge of reproductive rights is lack of education, $58.5 \%$ and $77 \%$ of in-school and out-of-school respondents respectively. For rural and urban comparisons, $64.3 \%$ of respondents in rural and $65 \%$ in urban areas also indicated lack of education. A higher proportion of female respondents $(74.1 \%)$ than male respondents $(56.8 \%)$ identified lack of education on human and reproductive rights as reason for their lack of knowledge. This further confirms why larger percentages of respondents could not identify the contents of adolescent sexual and reproductive rights, hence their nonresponse. $A$ respondent stated:

$R$ eally, before one can daim one's right, it is when you know that it is your right. If you don't know that you have that right, it becomes difficult for you to daim it. So, if theadolescents are not aware that it is their right to get the information, either from their parents, mass media or any other source, if they don't know, they cannot make daim to the right nor from the supposed authority. So peoplehaveto know, and the authority has to know that it belongs to somegroup (rights). W ithout this it will be difficult to claim.

Table 2 Respondents' Understanding of Reproductive $\mathrm{H}$ ealth (\%)

\begin{tabular}{|c|c|c|c|c|c|c|c|c|c|c|}
\hline Responses & $\begin{array}{r}\text { In- } \\
\text { school }\end{array}$ & $\begin{array}{r}\text { Out } \\
\text { of- } \\
\text { school }\end{array}$ & Rural & Urban & $\begin{array}{l}\text { Public } \\
\text { shool }\end{array}$ & $\begin{array}{l}\text { Private } \\
\text { school }\end{array}$ & $\begin{array}{l}\text { Urban } \\
\text { out-of- } \\
\text { school }\end{array}$ & $\begin{array}{l}\text { Rural } \\
\text { out-of- } \\
\text { school }\end{array}$ & Male & Female \\
\hline Childbearing & 22.3 & 29.5 & 20.3 & 29.0 & 30.2 & $\overline{16.1}$ & 31.0 & 28.0 & 22.5 & 27.0 \\
\hline $\begin{array}{l}\text { H ealth of } \\
\text { reproductive } \\
\text { organs }\end{array}$ & 13.0 & 3.0 & 14.0 & 5.3 & 6.3 & 18.8 & 3.0 & 3.0 & 11.7 & 7.3 \\
\hline $\begin{array}{l}\text { G iving birth to } \\
\text { many children } \\
\text { without any } \\
\text { problem }\end{array}$ & 0.8 & 15.0 & 6.0 & 5.0 & 0.5 & 1.8 & 13.0 & 17.0 & 4.9 & 6.2 \\
\hline $\begin{array}{l}\text { To bear more } \\
\text { children }\end{array}$ & 5.5 & 4.0 & 5.7 & 4.3 & 1.8 & 9.2 & 4.0 & 4.0 & 3.7 & 6.2 \\
\hline $\begin{array}{l}\text { Being physically } \\
\text { sound }\end{array}$ & 5.0 & 13.0 & 10.0 & 5.3 & 4.5 & 5.0 & 14.0 & 12.0 & 10.8 & 4.0 \\
\hline $\begin{array}{l}\text { K nowledge of } \\
\text { body and } \\
\text { sexuality }\end{array}$ & 13.5 & 5.0 & 9.0 & 12.3 & 11.3 & 15.6 & 10.0 & 0 & 9.0 & 12.8 \\
\hline $\begin{array}{l}\text { Theright ways } \\
\text { of doing } \\
\text { things }\end{array}$ & 0.3 & 0 & 0 & 0.3 & 0.5 & 0 & 0 & 0 & 0 & 0.4 \\
\hline No response & 39.8 & 30.5 & 35.0 & 38.3 & 45.0 & 33.5 & 25.0 & 36.0 & 37.3 & 36.1 \\
\hline
\end{tabular}


Table 3 Respondents' Explanation of Reproductive Rights

\begin{tabular}{|c|c|c|c|c|c|c|c|c|c|c|}
\hline Responses & $\begin{array}{r}\text { In- } \\
\text { school }\end{array}$ & $\begin{array}{r}\text { Out } \\
\text { of- } \\
\text { school }\end{array}$ & Rural & Urban & $\begin{array}{l}\text { Public } \\
\text { shool }\end{array}$ & $\begin{array}{l}\text { Private } \\
\text { school }\end{array}$ & $\begin{array}{l}\text { Urban } \\
\text { out-of- } \\
\text { school }\end{array}$ & $\begin{array}{l}\text { Rural } \\
\text { out-of- } \\
\text { school }\end{array}$ & Male & Female \\
\hline $\begin{array}{l}\text { Reproductive } \\
\& \text { sexual } \\
\text { health }\end{array}$ & 30.8 & 42.0 & 33.7 & 35.3 & 29.3 & 36.7 & 45.0 & 39.0 & 45.4 & 21.9 \\
\hline $\begin{array}{l}\text { Voluntary choice } \\
\text { in marriage }\end{array}$ & 37.5 & 56.0 & 40.7 & 46.7 & 37.8 & 42.2 & 58.0 & 54.0 & 53.4 & 32.5 \\
\hline $\begin{array}{l}\text { Family } \\
\text { formation, } \\
\text { timing and } \\
\text { spacing of } \\
\text { children }\end{array}$ & 33.3 & 49.5 & 32.7 & 44.7 & 36.9 & 33.0 & 50.0 & 49.0 & 42.9 & 33.9 \\
\hline $\begin{array}{l}\text { Right to have } \\
\text { access to full } \\
\text { information }\end{array}$ & 42.8 & 38.5 & 34.7 & 48.0 & 43.7 & 43.1 & 45.0 & 32.0 & 44.8 & 37.2 \\
\hline $\begin{array}{l}\text { E quality and } \\
\text { equity for } \\
\text { male and } \\
\text { female to } \\
\text { enablechoice }\end{array}$ & 23.5 & 25.0 & 17.0 & 31.0 & 25.2 & 27.5 & 40.0 & 10.0 & 29.0 & 18.2 \\
\hline $\begin{array}{l}\text { Sexual and } \\
\text { reproductive } \\
\text { security }\end{array}$ & 29.0 & 45.0 & 31.0 & 37.7 & 28.8 & 33.0 & 46.0 & 44.0 & 42.3 & 25.2 \\
\hline $\begin{array}{l}\text { Right to } \\
\text { privacy and } \\
\text { confidentiality }\end{array}$ & 32.0 & 40.5 & 28.7 & 41.0 & 33.3 & 35.3 & 49.0 & 32.0 & 44.1 & 24.1 \\
\hline $\begin{array}{l}\text { Right to form } \\
\text { an association }\end{array}$ & 33.3 & 32.0 & 28.3 & 37.3 & 34.2 & 34.9 & 40.0 & 24.0 & 42.6 & 21.5 \\
\hline
\end{tabular}

Looking at the socialization process, another respondent remarked:

The truth is that most of our parents themselves were not informed about these until they got married. So outside marriage, they feel embarrassed themsel ves to call a child and start to lecture. It is not shyness, they don't think of it as necessary. It is what you know that you will explain.

\section{A dolescent Sex ual and R eproductive $R$ ights and $D$ evelopment}

Figure 4 shows that majority of the respondents, irrespective of schooling status, condition or type of settlement, agreed that realising adolescent sexual and reproductive rights would contribute to their development and that of the nation.

A nalysis revealed that $73.5 \%$ of in-school adolescents, $88 \%$ of out-of-school adolescents, $84 \%$ of rural residents and $72.7 \%$ of urban residents are favourably disposed to positive relationship between sexual and reproductive rights and development. The following were their responses:

Since they know everything about sex uality, even if a boy or girl wants to have sex, they will know what to do so as not to disturb their education or having diseases. It will also allow them to do whatever they want in future. 


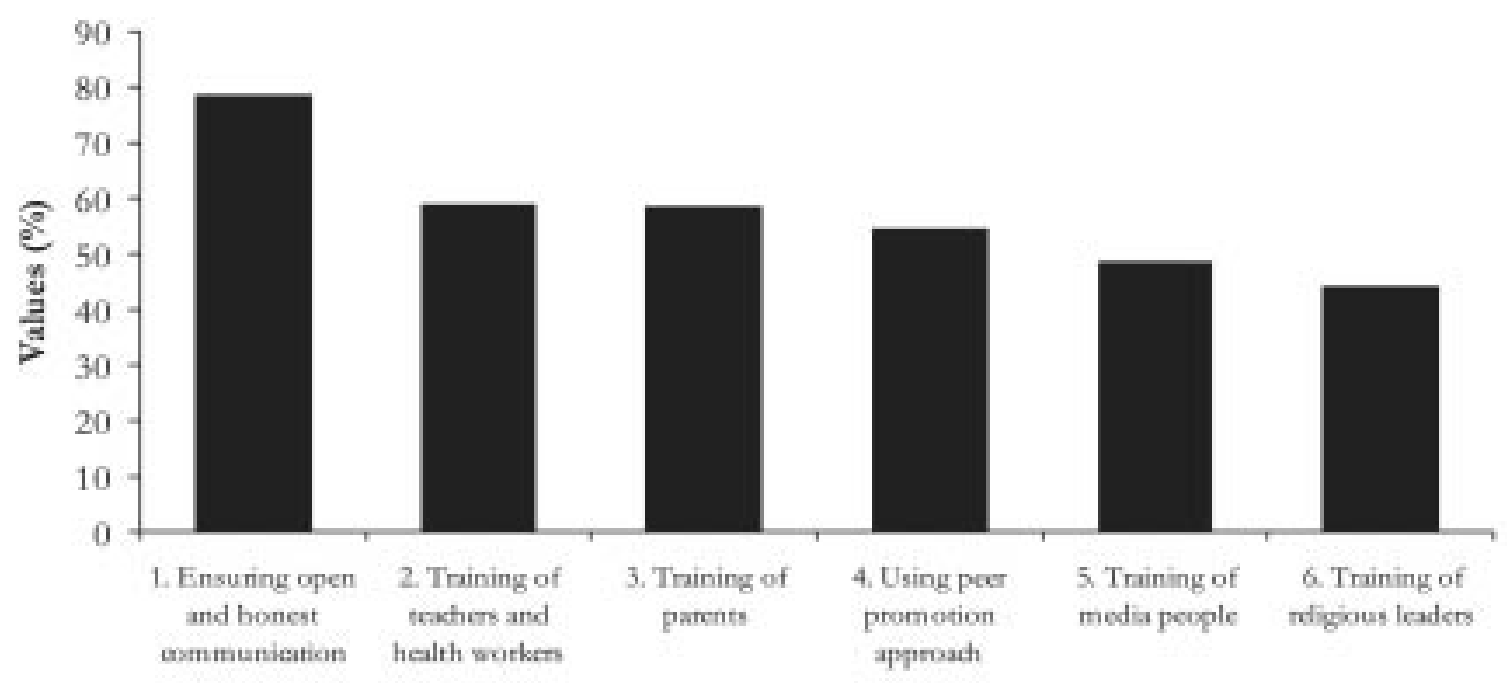

Responses

F igure 5 Respondents' Opinion on Strategies for Raising Awareness on Adolescent Sexual and Reproductive Right

Things have changed from the time of our parents. There is violence, rape and cases of unwanted pregnancies everywhere. W hen they know that their children are exposed to all thesehazards, they should educate us to know how to protect and prevent ourselves.

It will be by $G$ od's grace. If they hear and know their rights, with thehelp of government they will be able to exercise it, and it will change and better their future. This will help the youths.

These findings confirm that adolescents do not underestimate the risk of irresponsible sexual behaviour, and contradict the proposition that they would make no efforts to know their sexual and reproductive rights and exercise them. The findings support the findings of UNFPA ${ }^{19}$ that reproductive and sexual rights for the individual, whether man or woman, are foundation stones of posterity and a better quality of life for all people. As such, they are absolutely essential to any hope of achieving sustainable development.
Strategies for I mproving A wareness $R$ aising on $A$ dolescent $S$ ex ual and $R$ eproductive $R$ ights

Figure 5 shows suggestions on strategies to adopt to raise awareness on sexual and reproductive rights of adolescents. In all $58.7 \%$ and $58.5 \%$ suggested training of teachers/ health workers and parents respectively, while $54.5 \%$ were of the opinion that peer promotion approach should be continued and emphasised. A female adolescent from a private school remarked:

I think it should also be made compulsory for our parents to teach us, since it is our rights. If they can make it a right, then it should be made into law. The government should pass a bill to the house about it that our parents should talk about it. Then punishment should follow.

Moise ${ }^{13}$ confirmed that informing youth about their sexual and reproductive rights helps them develop responsiblesexual behaviour. Some $48.5 \%$ and $44 \%$ were of the view that media 
personnel and religious leaders should be trained on this important issue. In all, $78.5 \%$ strongly suggested that open and honest communication about these issues should be ensured. These suggestions will go a long way in alleviating teachers' discomforts with the subject, reducing opposition from traditionalists and religious groups, and the unknown fear of parents and criticisms. The peer education approach will ensure young people's active involvement in advocacy for their own sexual and reproductive rights ${ }^{13}$ as well as equip health workers to treat young people. The following view was expressed by youth at Braga Forum in 1998:

We want the following from health professionals: be confidential with us, provide us with information and services weneed, accept us as we are, do not moralise or demoraliseus, use language or means we understand, ask and respect our opinions about the services, allow us to decide for ourselves, mak e us feel welcome and comfortable, don't judge us, provide services at the time and within the time frame we have available.

If these voices of the young persons are implemented, it will create a conducive environment. This will empower adolescents to be aware of, knowledgeable about and exercise their sexual and reproductive rights. It will also ensure a promising future for them and make the world a comfortable place for them to live.

\section{Conclusion}

E mphasis has been on sexual and reproductive rights for some years now, especially in relation to adolescents. It is believed that if this were a reality it would be translated into action to reduce the incidence of teenage pregnancies and infection with STD s including HIV/ AIDS. M oreover, it is envisaged that development, mostly of females, would be achieved through this means as well as resolving other issues as sexual and gender violence, etc. O ne of the ways through which this could be achieved is ensuring access to information and education about sexual and reproductive rights.

This study, which was conducted seven years post-ICPD, revealed that the achievements of the various treaties and agreements signed are far from the reality and expectations. The reasons are obvious. Information and education in this regard have been minimal, resulting in the inability of adolescents to exercise their sexual and reproductive rights.

\section{Limitations of the Study}

This study was conducted in two out of the sixteen LGAs in Lagos State in south-western $\mathrm{N}$ igeria. The assumptions in the study may not apply to target groups of south-western $\mathrm{N}$ igeria generally, as this geopolitical zone consists of six states, out of which only one state has been selected. Further research should be conducted to cover other states in this zone to make the findings more representative. To justify this further, despite the fact that the culture of the people in this region is similar, there are still variations that could have impact on the results of the findings.

Despite the fact that a combination of methods was used in gathering data, the issue of religion was not properly explored to find out the strength of religion in addressing the issue of adolescent sexual and reproductive rights. This is vital, considering how religion is taken seriously amongst the study community.

The findings of the study revealed that the media is a major channel of information dissemination on adolescent reproductive rights, the issue of bias is a major factor that may hinder the usefulness of such information to adolescents.

\section{Acknowledgement}

The author appreciates the input of Prof. U che Isiugo-A banihe, Dr D ele Jegede and Dr Lanre 
112 A frican Journal of $\mathrm{R}$ eproductive $\mathrm{H}$ ealth

O lutayo, all of the Department of Sociology, U niversity of I badan, I badan, for their valuable comments and constructive suggestions during the questionnaire design and presentation of findings. I sincerely appreciate the interest of Prof. E zekiel A dewale $O \mathrm{ke}$, $\mathrm{H}$ ead of the $\mathrm{D}$ epartment of Sociology, U niversity of I badan, I badan, for creating time to read and make input to the manuscript. In addition, the efforts of research assistants in conducting the fieldwork and the respondents for their time are commended.

\section{References}

1. A dinmaJIB and O kekeAO. The pill: perception and usage among $\mathrm{N}$ igerian students. $\mathrm{A}$ dv $\mathrm{C}$ ontracep 1993; 9: 345-346.

2. Ajayi AA, M arangu LT, M iller J and Paxman JM . A dolescent sexuality and fertility in K enya: a survey of knowledge, perceptions and practices. Stud Fam Plann 1991; 22(4): 205-216.

3. Barker $G$ and Rich S. Peer interaction and traditional and modern influences on adolescent sexuality in $\mathrm{N}$ igeria and $\mathrm{K}$ enya. Findings from focus group discussions. CPO / PCC, Washington DC, 1991, p. 7.

4. Boohene $E$, Tzodzai J, $H$ ardee-Cleaveland $K$, Weirs and Janowitz B. Fertility and contraceptive use among young adults in $\mathrm{H}$ arare, Z imbabwe. Stud Fam Plann 1991; 22(4): 264-271.

5. E su-Williams E. Rural women's perception of their health: astudy in Cross Rivers in N igeria. Report prepared for Women in N igeria - Cross River State, Calabar. U niversity of Calabar, N igeria, 1991.

6. Family Care International. A ffirming R eproductive $H$ ealth nd Rights A ction: The 21st C entury. 1994.

7. FM O H. HIV Sentinel Surveillance Report, 1999.

8. IPPF. 1995-1996 Annual Report.

9. Ikeja LGA. Ikeja: The C orporate L GA . Lagos: Longman N igeria, 1996.

10. I korodu LGA. Caretak er Committee A n A ccount of Stewardship - TheO ladeinde Y ears. Lagos: A Imond Communications, 1996.
11. Irionoye 0 O, Babatunde $\mathrm{AO}$ and A dinma NE. Precautionary measures used by adolescents to prevent sexually transmitted diseases and preganncy in Ile-Ife, $\mathrm{N}$ igeria. $\mathrm{N}$ ig Sch $\mathrm{H}$ ealth] 2000; $12(1 \& 2): 18-26$.

12. LemaV M. Sexual behavior, contraceptive practice and knowledge of reproductive biology among adolescent secondary school girls in $\mathrm{N}$ airobi. $\mathrm{E}$ A fr M ed J 1990; 67(2): 86- 94.

13. MoiseF. Sexual and reproductive rights of young people: $\mathrm{H}$ aiti experience - findings of a project implemented by theF oundation for Reproductive $\mathrm{H}$ ealth and Family E ducation, $\mathrm{H}$ aiti. Sex ual $\mathrm{H}$ ealth Exchange 1999; 4: 5.

14. N ational Report. Research on policies and legislation affecting adolescents in N igeria. 1992.

15. O sakwe $G$ and Martin-H ilber A. Women's sexuality and fertility in $\mathrm{N}$ igeria: breaking the culture of silence. In: Rosalind PP and K aren J (E ds.). N egotiating Reproductive R ights: W omen's Perspectives $A$ cross $C$ ountries and $C$ ultures. London: Zed Book Publishers, 1998, p. 180-216.

16. Population Reference Bureau. A dolescent Sexual $A$ ctivity and $C$ hildbearing in $L$ atin $A$ merica and the C arribean: R isk s and $C$ onsequences. Washington D C: Population Reference Bureau, 1992.

17. Rakesh R. Mustapha K. The varieties of sexual experience of the street children: The M wanzaTanzania Project. In: L earning A bout Sex uality: A Practical B eginning. N ew York: Population Council Inc., 1996.

18. United N ations. A dolescent $R$ eproductive $B$ ehavior : $E$ vidence from D eveloping C ountries. N ew York: ST / E SA/ SE R.A/ 109/ Add. 1. 1989.

19. UN FPA. The R ight to Choose: R eproductive $R$ ights and R eproductiveH ealth. U N FPA, 1997.

20. WHO. Approaches to adolescent health and development: principles for success. A joint WH O / IY F M eeting, G eneva, 1992.

21. WHO. The Second D ecade: I mproving A dolescent $H$ ealth and D evelopment. G eneva: WH O, 1998.

A frican Journal of Reproductive $H$ ealth $V$ ol. $9 \mathrm{~N} 0.1$ A pril 2005 